\title{
Influences of submerged plant collapse on diet composition, breadth, and overlap among four crane species at Poyang Lake, China
}

\author{
Jinjin Hou', Lei Li ${ }^{1,2,3}$, Yafang Wang ${ }^{1}$, Wenjuan Wang ${ }^{1,2,3^{*}}$ (D) Huiying Zhan ${ }^{4}$, Nianhua Dai ${ }^{5}$ and Ping Lu ${ }^{5}$
}

\begin{abstract}
Background: Interannual variation in resource abundance has become more unpredictable, and food shortages have increasingly occurred in the recent decades. However, compared to seasonal fluctuations in resource abundance, the influences of interannual variation in resource abundance on the dietary niches of consumers remain poorly understood. Poyang Lake, China, is a very important wintering ground for the globally endangered Siberian Crane (Leucogeranus leucogeranus), White-naped Crane (Grus vipio), and Hooded Crane (G. monacha), as well as the non-endangered Eurasian Crane (G. grus). Tubers of Vallisneria spp., the dominant submerged macrophytes at Poyang Lake, is an important food for cranes. Nevertheless, submerged macrophytes have experienced serious degradation recently. In this study, we used metabarcoding technology to explore the consequences of Vallisneria tuber collapse on the diet compositions, breadths, and overlaps of the four crane species based on fecal samples collected in winter 2017 (a year with tuber collapse) and winter 2018 (a year with high tuber abundance).

Results: Compared to previous studies, our study elucidates crane diets in an unprecedented level of detail. Vallisneria tubers was confirmed as an important food source of cranes. Surprisingly, the grassland plant Polygonum criopolitanum was also found to be an important food source in the feces of cranes. Agricultural fields were important foraging sites for Siberian Cranes, White-naped Cranes, and Hooded Cranes, providing foods that allowed them to survive in winters with natural food shortages. However, the three crane species preferred natural wetlands to agricultural fields when the abundance of natural foods was high. The abundance of Vallisneria tubers, and probably P. criopolitanum, greatly influenced the dietary compositions, breadths and overlap of cranes. During periods of preferred resource shortage, White-naped Cranes and Hooded Cranes widened their dietary niches, while Siberian Cranes maintained a stable niche width. The dietary niche overlap among crane species increased substantially under conditions of plentiful preferred food resources.

(Continued on next page)
\end{abstract}

\footnotetext{
*Correspondence: wangwj@ncu.edu.cn; wangwj870120@163.com

${ }^{1}$ Jiangxi Province Key Laboratory of Watershed Ecosystem Change and Biodiversity, Center for Watershed Ecology, Institute of Life Science and School of Life Science, Nanchang University, Nanchang 330031, China ${ }^{2}$ Key Laboratory of Poyang Lake Environment and Resource Utilization, Ministry of Education, Nanchang University, Nanchang 330031, China Full list of author information is available at the end of the article
}

(c) The Author(s). 2021 Open Access This article is licensed under a Creative Commons Attribution 4.0 International License, which permits use, sharing, adaptation, distribution and reproduction in any medium or format, as long as you give appropriate credit to the original author(s) and the source, provide a link to the Creative Commons licence, and indicate if changes were made. The images or other third party material in this article are included in the article's Creative Commons licence, unless indicated otherwise in a credit line to the material. If material is not included in the article's Creative Commons licence and your intended use is not permitted by statutory regulation or exceeds the permitted use, you will need to obtain permission directly from the copyright holder. To view a copy of this licence, visit http://creativecommons.org/licenses/by/4.0/. The Creative Commons Public Domain Dedication waiver (http://creativecommons.org/publicdomain/zero/1.0/) applies to the data made available in this article, unless otherwise stated in a credit line to the data. 
(Continued from previous page)

Conclusions: Our study emphasizes the superior quality of natural wetlands compared to agricultural fields as foraging habitats for cranes. To provide safer and better foraging areas for cranes, it is urgent to restore the submerged plants at Poyang Lake. While high dietary niche overlap is often interpreted as intense interspecific competition, our study highlights the importance of taking food abundance into account.

Keywords: Agricultural fields, Food shortage, Hooded crane, Siberian crane, Vallisneria tuber, White-naped crane

\section{Background}

Interspecific competition is an important mechanism in structuring ecological communities [1, 2]. Competition may lead to resource (food, habitat, time) partitioning and facilitate the coexistence of sympatric species $[1,3$, 4]. Diet partitioning has been suggested to be the primary mechanism of coexistence of many insects [5], fish [6], snakes [7], birds [8], and mammals [9].

Many ecosystems are characterized by temporal variations in resource availability, which may subsequently influence dietary niche of birds [10-12]. Migratory birds may also encounter strikingly different feeding conditions along their flyways $[13,14]$. Therefore, it is critically important that birds are able to adjust their diets to explore a wide range of food resources $[11,15]$. Numerous examples of dietary flexibility exist. Dunlins (Calidris alpine) [11], Semipalmated Sandpiper (C. pusilla) [16], Hooded Crane (Grus monacha) [17], and Blacknecked Crane (G. nigricollis) [18] have all varied their diets with changes in prey availability. In contrast, strong dependence on a few prey types can make birds vulnerable to the reduction of prey abundance, as has been the case for Red Knot (C. canutus) feeding on Horseshoe Crab (Limulus polyphemus) eggs [19].

Optimal foraging theory is often used to predict the foraging decisions of animals [20,21]. According to the theory, when resources are abundant, species should consume the most profitable food items with high nutrition and accessibility while ignoring less profitable foods. When preferred food items become depleted, species add less profitable foods to their diet [22, 23]. Great Knots $(C$. tenuirostris), for example, changed their diet composition and prey selection to include prey items that were physically more difficult to digest after a severe decline in food abundance and quality [24]. Optimal foraging theory predicts a reduction in dietary niche breadth during seasons of high food abundance and an increasing trend during seasons of low food abundance. This pattern of niche width variation has been observed across a range of taxa, including birds [12, 25], mammals [26, 27], fish [28, 29], and invertebrates $[30,31]$. The theory also predicts an increase in dietary niche overlap between species when resources are abundant [7, 32, 33]. The increased overlap may be related to the reduced competitive interaction between species due to great resource availability. For example, there was an absence of dietary niche partitioning among shorebird species at Delaware Bay, USA, when the density of their primary prey Horseshoe Crab eggs was high [34]. Extensive degree of dietary niche overlap has also been revealed among seabird species breeding on the Argentinean Patagonian coast with superabundance of pelagic fish [35].

Understanding how dietary niche changes for any species as fluctuations in food abundance occurs is useful for designating management strategies to preserve biodiversity and ecosystem services $[32,36]$. However, most research is focused on the influences of seasonal variation in food abundance on dietary niches [10, 11, 32, 37]. Due to global climate change and increased human disturbance, interannual variation in resource abundance has increased in frequency and intensity, promulgating food scarcity at higher rates in recent decades [38-40]. For example, floods that negatively affect submerged plant growth and even lead to mass death of plants have become more frequent at Poyang Lake, China [41-43], which may threaten the survival of birds that feed on them $[38,44,45]$. Seasonal variation in food abundance occurs regularly. Animals have evolved strategies to cope with the predictable environmental variation [46]. Interannual variation in food abundance occurs less frequently, although its frequency and intensity have recently increased [38-40]. Without sufficient evolutionary time, animals may not adapt well to the interannual variation; thus, it may pose a challenge for many taxa $[19,47,48]$.

Cranes are among the most threatened families of birds [49]. Poyang Lake, which is located on the southern bank of the Yangtze River, China, is an important wintering ground for cranes in East Asia (Fig. 1). It supports approximately $98 \%$ of the estimated global population of IUCN Critically Endangered Siberian Crane (Leucogeranus leucogeranus), approximately $18 \%$ of the estimated global population of Vulnerable White-naped Crane (Grus vipio), approximately 3\% of the estimated global population of Vulnerable Hooded Crane, and approximately half of the Chinese population of Eurasian Crane (G. grus) [50-52]. With the degradation of lakes in the middle and lower Yangtze River floodplain, Poyang Lake is playing an increasingly important role in crane protection, especially for the Siberian Crane [53, 


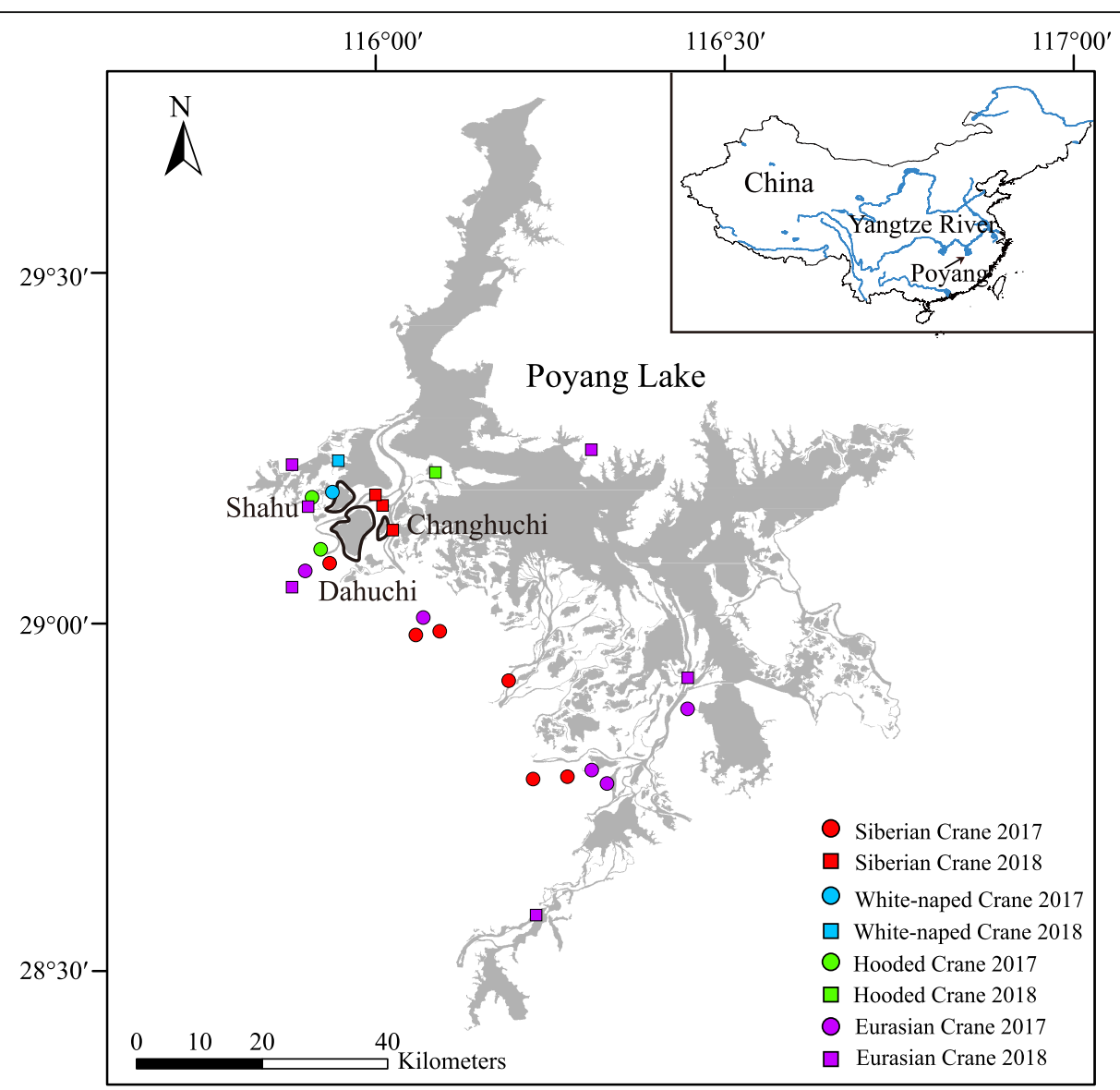

Fig. 1 Maps showing the three Vallisneria tuber survey sublakes (Dahuchi, Shahu, and Changhuchi) and the sampling sites of crane feces at Poyang Lake. Circles and squares represent sampling sites in the winters of 2017 and 2018, respectively. The colors of the circles and squares correspond to the crane species: red: Siberian Crane; blue: White-naped Crane; green: Hooded Crane; and purple: Eurasian Crane. The base map shows the inundation area of Poyang Lake in winter 2008, when the water level was similar to the historical average water level

54]. It has been suggested that other than Poyang Lake, there are no alternative wintering sites for Siberian Cranes remaining in the Yangtze River floodplain [49].

Tubers of Vallisneria spp., the dominant submerged macrophytes at Poyang Lake, is an important food source for cranes $[38,55,56]$. However, submerged macrophytes have degraded seriously in recent decades [57-60]. They were widely distributed throughout Poyang Lake in previous years, but were restricted to small areas in 2012 [58]. The Vallisneria tuber density and biomass at three sublakes (Dahuchi, Shahu and Meixihu) of Poyang Lake declined greatly in the winters from 1999 to 2017 [57, 60]. The frequency and range of Vallisneria tuber collapse have also increased because of frequently occurring summer flood and autumn drought, extensive aquaculture, declining water quality, and other factors $[38,57,60]$.

Tuber collapse has led to dietary and foraging habitat shifts of cranes. For example, the tuber collapses in the winters of 2015 and 2016 drove thousands of Siberian Cranes, for the first time, to switch from foraging in shallow waters they typically used to paddy fields and lotus ponds [57, 61]. Their main foods changed from Vallisneria tubers to rice (Oryza sativa) seeds and lotus (Nelumbo nucifera) rhizomes [62]. Many White-naped Cranes, Hooded Cranes and Eurasian Cranes also moved from natural wetlands to forage in paddy fields $[63,64]$. Diet shifts may influence the dietary niche width and overlap between crane species and subsequently the competition level and fitness of cranes. Given the highly endangered status of cranes and the importance of Poyang Lake in crane protection, it is important to understand the consequences of Vallisneria tuber collapse on diets and competition levels among crane species so that effective protection measures can be implemented.

Traditional dietary analysis methods include direct observation of foraging animals and microscopic examination of feces or gut contents. While these approaches have been suggested to be useful in some cases, they also exhibit methodological limitations [65-67]. The main drawbacks are that the methods can be inaccurate and labor-intensive $[65,68]$. Recently, the emergence of DNA metabarcoding has provided new perspectives for 
diet analysis [65]. This method is based on amplifying and high-throughput sequencing a standardized DNA region from stomach contents or feces, and subsequently comparing it to a reference database for identification of the consumed species [65]. Compared to traditional methods, DNA metabarcoding generally provides higher taxonomic resolution, identifies more food items, and can simultaneously analyze a larger number of samples [69-71]. After its first application in assessment of the diets of Australian Fur Seals (Arctocephalus pusillus doriferus) [72], metabarcoding has been used successfully to study diets of herbivores $[9,73]$, carnivores $[69,74]$ and omnivores [75, 76].

In this study, we used metabarcoding technology to explore the consequences of Vallisneria tuber collapse on the diet compositions, niche breadths, and niche overlaps of the four crane species at Poyang Lake. Fecal samples were collected in winter 2017 (i.e., 2017/2018; a year with Vallisneria tuber collapse) and winter 2018 (i.e., 2018/2019; a year with high Vallisneria tuber abundance; see Results for details). We first explored the diets of the four crane species and their interannual variations. Most previous dietary studies of cranes were based on traditional direct observation or microscopic examination. Here, we hoped to apply the metabarcoding method to provide a more accurate and comprehensive understanding of the cranes' diets. We then evaluated the role of agricultural fields in crane protection. Vallisneria tuber collapses have driven thousands of cranes to feed in agricultural fields [61, 64]. However, the proportion of domesticated species in the diets of the four crane species has not previously been quantified. Here, we determined the relative dietary importance of domesticated species in the feces of cranes. Finally, we assessed the consequences of Vallisneria tuber collapse on the dietary niche width and overlap among crane species. To do so, we compared the niche breadths and overlaps in winter 2017 and winter 2018 with different Vallisneria tuber abundances. Although we focused on cranes at Poyang Lake, our findings can provide a reference for dietary shifts of consumers in degraded wetlands worldwide.

\section{Results}

\section{Variation in Vallisneria tuber abundance}

We investigated the density and biomass of Vallisneria tubers at three sublakes (Dahuchi, Shahu and Changhuchi; Fig. 1) of Poyang Lake. The average tuber density and biomass were 6.68 tubers $/ \mathrm{m}^{2}$ and $0.54 \mathrm{~g} / \mathrm{m}^{2}$, respectively, in winter 2017 (Table 1). The density and biomass rapidly increased to 34.57 tubers $/ \mathrm{m}^{2}$ and $4.11 \mathrm{~g} / \mathrm{m}^{2}$ in winter 2018. The historical average tuber density and biomass at three sublakes (Dahuchi, Shahu and Meixihu) of Poyang Lake were $10.33( \pm 11.27 \mathrm{SD})$ tubers $/ \mathrm{m}^{2}$ and
Table 1 The density and biomass of Vallisneria tubers at three sublakes (Dahuchi, Shahu, and Changhuchi) of Poyang Lake in the winters of 2017 and 2018

\begin{tabular}{llll}
\hline Winter & Sublake & $\begin{array}{l}\text { Tuber density } \\
\left(\text { tubers } / \mathbf{m}^{2}\right)\end{array}$ & $\begin{array}{l}\text { Tuber biomass } \\
\left(\mathbf{g} / \mathbf{m}^{2}\right)\end{array}$ \\
\hline 2017 & Dahuchi & 9.80 & 0.97 \\
& Shahu & 0.28 & 0.02 \\
& Changhuchi & 9.97 & 0.62 \\
& Average & 6.68 & 0.54 \\
2018 & Dahuchi & 6.41 & 0.65 \\
& Shahu & 8.97 & 0.60 \\
& Changhuchi & 88.32 & 11.07 \\
& Average & 34.57 & 4.11 \\
\hline
\end{tabular}

$3.26( \pm 3.68 \mathrm{SD}) \mathrm{g} / \mathrm{m}^{2}$ in the winters from 1999 to 2016 [57]. Tuber density in winter $2017(\mathrm{t}=1.33, P=0.201)$ and tuber biomass in winter $2018(\mathrm{t}=-0.94, P=0.361)$ did not differ from the historical average values. However, tuber biomass in winter 2017 was lower than the historical average values $(\mathrm{t}=3.10, P=0.007)$, and tuber density in winter 2018 was higher than the historical average values $(t=-8.88, P=0.000)$. Therefore, winter 2017 represented a year with tuber collapse, while winter 2018 represented a year with high tuber abundance. Coinciding with the changes in tuber abundance, a total of 4014 individuals of Siberian Cranes, White-naped Cranes and Hooded Cranes were recorded in agricultural fields adjacent to Poyang Lake in winter 2017 [63], while none of the three crane species was recorded in agricultural fields in winter 2018 [77].

\section{Collection statistics}

In total, we collected 129 fecal samples, with 60 samples from winter 2017 and 69 samples from winter 2018 (Fig. 1; Additional file 1: Table S1). We collected 42 fecal samples of Siberian Cranes from 2 sublakes, 4 rice paddies, and 1 lotus pond; 20 fecal samples of White-naped Cranes from 2 sublakes and 1 rice paddy; 19 fecal samples of Hooded Cranes from 2 sublakes and 1 rice paddy; and 48 fecal samples of Eurasian Cranes from 3 sublakes and 6 rice paddies. We also collected 38 plant species commonly seen at Poyang Lake to construct a DNA barcode reference library. By downloading sequences from GenBank and sequencing by ourselves, we constructed a DNA barcode reference library containing 62 plant species.

\section{High-throughput DNA sequencing}

The chloroplast trnL intron was selected as a barcode because of its high taxonomic coverage and resolution, especially for wetland plants $[70,78]$. The sequencing of the 129 fecal samples yielded a total of $9,284,819$ reads. After quality filtering, 8,502,418 reads were obtained. 
The average number of reads per sample was 65,910 $( \pm$ $26,276 \mathrm{SD}$ ), and the average number of operational taxonomic units (OTUs) per sample was 43 ( $\pm 15 \mathrm{SD}$ ). To evaluate the sequencing and sampling adequacy, individual-, species-, and sample-based rarefaction curves were built. With the sample sequencing reads increased, the individual-based rarefaction curves reached plateau in most cases (Additional file 1: Figure S1) and the speciesbased rarefaction curves reached plateau in the four crane species (Fig. 2a). Therefore, our sequencing depth was roughly adequate to capture the numbers of OTUs present. The sample-based rarefaction curves for each crane species reached plateau in all cases as the sampling sizes increased (Fig. 2b), suggesting that we acquired sufficient fecal samples. After comparison to the local DNA reference database, $98.99 \%$ of the total reads were assigned to specific plant taxa. Most of the reads that were not assigned to specific plant taxa had low frequency. In total, we identified 29 plant taxa, including 23 species, 4 genera, and 2 families.

\section{Diet compositions of the four crane species}

We used relative read abundance (i.e., the percentage of DNA belonging to each food item in each sample; RRA), which provides a more accurate view of species diet than frequency of occurrence (i.e., the number of samples that contain a given food item), to summarize dietary data [79]. Twenty-two food items were identified in the feces of Siberian Cranes in the two winters, including 17 species, 3 genera, and 2 families (Fig. 3; Additional file 1: Table S2). Rice (RRA $=72.85 \%$ ), lotus $(12.01 \%)$, and Polygonum criopolitanum (11.99\%) were the dominant food items in the feces (i.e., proportion $>10 \%$ ) in winter 2017, and Vallisneria (56.12\%) and P. criopolitanum (40.87\%) were the dominant food items in winter 2018. Twenty-five food items were identified in the feces of White-naped Cranes, including 20 species, 3 genera, and 2 families. Tulipa edulis (37.37\%), Potentilla limprichtii (18.69\%), P. criopolitanum (16.52\%), and Carex spp. (10.75\%) were the dominant food items in the feces in winter 2017, and $P$. criopolitanum (84.41\%) was the dominant food item in winter 2018. Twenty-two food items were identified in the feces of Hooded Cranes, including 18 species, 3 genera, and 1 family. P. limprichtii (65.36\%) and Carex (27.39\%) were the dominant food items in the feces in winter 2017 , and P. criopolitanum (88.76\%) was the dominant food item in winter 2018. Twenty-two food items were identified in the feces of Eurasian Cranes, including 17 species, 3 genera, and 2 families. Rice (61.20\%) and P. limprichtii (23.94\%) were the dominant food items in the feces in winter 2017, and $P$. criopolitanum $(55.77 \%)$ and rice $(27.40 \%)$ were the dominant food items in winter 2018. Diet compositions of Siberian Cranes (Pearson correlation $=0.05$, $P=0.77$ ), White-naped Cranes (Pearson correlation = $0.30, P=0.08$ ) and Hooded Cranes (Pearson correlation $=-0.04, P=0.83$ ) were not correlated between winter 2017 and winter 2018, suggesting great interannual variations in food sources. Diet composition of Eurasian Cranes was correlated $($ Pearson correlation $=$ $0.40, P=0.02$ ) between the two winters, suggesting limited interannual variation in food sources.

Vallisneria tubers were an important food source for the four crane species, especially Siberian Cranes, in winter 2018. The proportion of Vallisneria was 56.12, 5.12, 8.50, and $7.34 \%$ in the feces of Siberian Cranes, White-naped Cranes, Hooded Cranes, and Eurasian Cranes, respectively, in winter 2018 (Fig. 3; Additional file 1: Table S2). In winter 2017, when Vallisneria tuber abundance was low, the proportion of Vallisneria was less than $1 \%$ in the feces of the four crane species.

Domesticated species identified in crane feces included rice and lotus. The proportions of domesticated species in the feces of Siberian Cranes (84.85\%) and White- (a) Species-based rarefaction curve

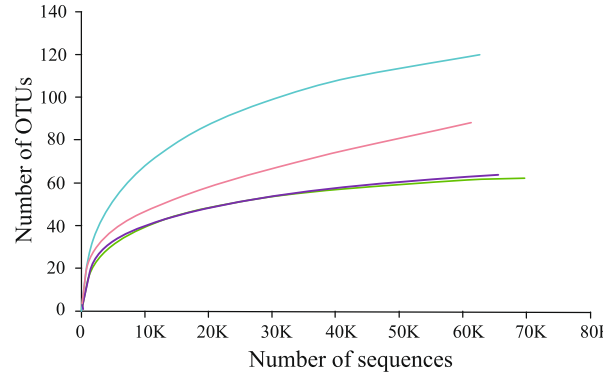

(b) Sample-based rarefaction curve

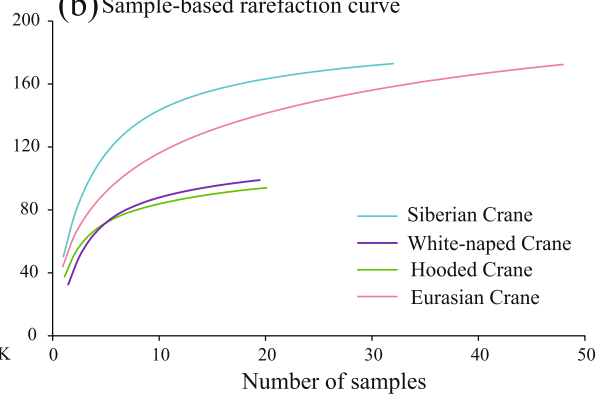

Fig. 2 a Species-based and $\mathbf{b}$ sample-based rarefaction curves. The species- and sample-based rarefaction curves, built by randomly resampling sequences and samples respectively at increasing levels of accumulation, indicate whether the sequencing depth and sampling size were sufficient to characterize the diversity of dietary items. The colors of the curves correspond to the crane species: blue: Siberian Crane; purple: White-naped Crane; green: Hooded Crane; and red: Eurasian Crane 


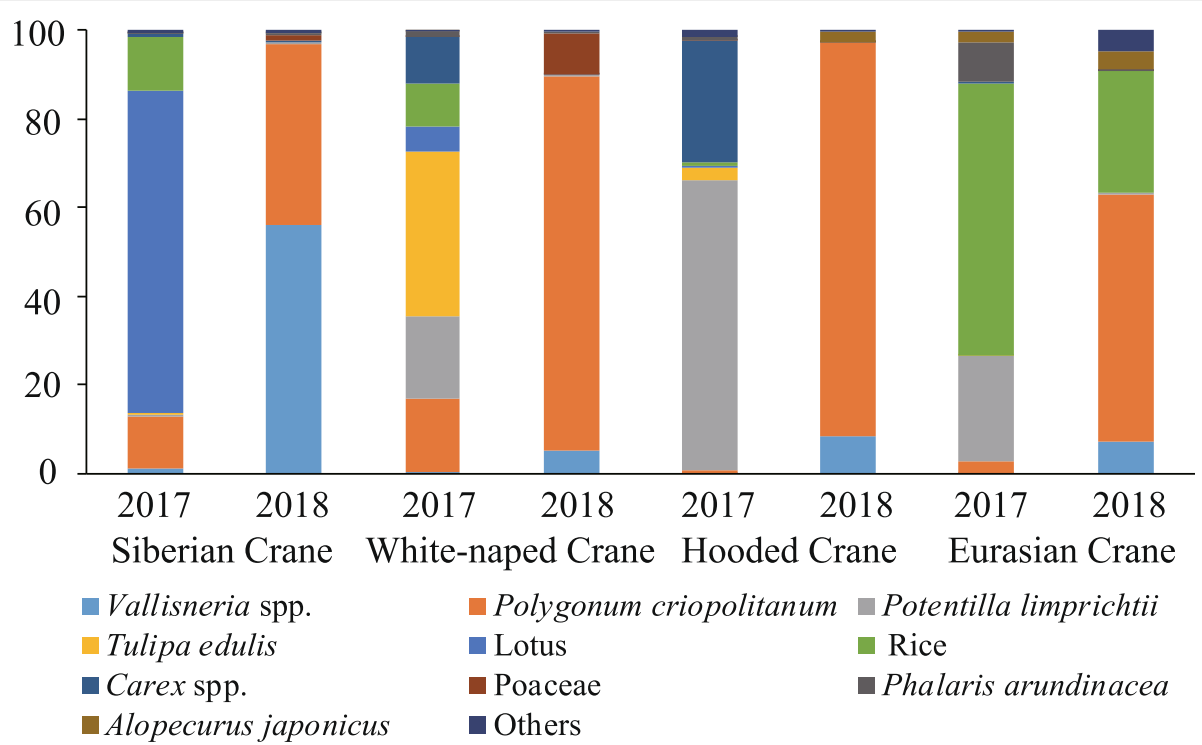

Fig. 3 Food items in the feces of Siberian Cranes, White-naped Cranes, Hooded Cranes, and Eurasian Cranes in the winters of 2017 and 2018 at Poyang Lake

naped Cranes (15.09\%) were high in winter 2017, but declined to $0.00 \%$ in winter 2018 (Fig. 3; Additional file 1: Table S2). Domesticated species occupied a small proportion in the feces of Hooded Cranes in winter 2017 (1.30\%), but declined to $0.00 \%$ in winter 2018 . The proportions of domesticated species in the feces of Eurasian Cranes were high in both winters, with $61.20 \%$ in winter 2017 and $27.40 \%$ in winter 2018.

\section{Dietary niche breadth and overlap among crane species}

The numbers of food items, dietary niche breadth and Shannon-Wiener diversity values for Siberian Cranes and Eurasian Cranes in winter 2017 were similar to those in winter 2018 (Table 2). Values of all three parameters for White-naped Cranes and Hooded Cranes were higher in winter 2017 than in winter 2018. Dietary niche breadth of the four crane species was $<0.20$ in both winters, indicating low niche breadth.

Dietary niche overlap among crane species ranged from 0.02 to 0.49 in winter 2017, but increased to 0.62 to 0.99 in winter 2018 (Table 3). Nonmetric multidimensional scaling (NMDS) analysis also indicated overlap increases in winter 2018 (Fig. 4). No overlap values were lower than expected by chance in the two winters. The overlap values were not higher than expected by chance in winter 2017. However, all values showed a high degree of overlap in winter 2018 [ $\mathrm{P}(\mathrm{Obs}>=$ null $)<0.05$ ]. Overlap between White-naped Cranes and Hooded Cranes was the highest among the four crane species in both winters.

\section{Discussion}

\section{Diet composition}

To the best of our knowledge, our study is the first to explore crane diets using metabarcoding techniques. Almost all previous studies have relied on traditional direct observation or microhistological methods. By using metabarcoding technology, we were able to elucidate crane diets at greater detail than previously known. The improved knowledge might be due to the ability of metabarcoding to provide a more comprehensive perspective and more details on food sources than traditional methods $[66,67,80]$. Metabarcoding is able to detect a variety of smaller and softer bodied food items

Table 2 Number of food items, dietary niche breadth, and Shannon-Wiener diversity values for Siberian Cranes, White-naped Cranes, Hooded Cranes, and Eurasian Cranes at Poyang Lake in the winters of 2017 and 2018

\begin{tabular}{|c|c|c|c|c|c|c|}
\hline & \multicolumn{2}{|c|}{ Number of foods } & \multicolumn{2}{|c|}{ Dietary niche breadth } & \multicolumn{2}{|c|}{ Shannon-Wiener diversity } \\
\hline & 2017 & 2018 & 2017 & 2018 & 2017 & 2018 \\
\hline Siberian Crane & 16 & 17 & 0.05 & 0.07 & 0.91 & 0.85 \\
\hline White-naped Crane & 18 & 15 & 0.20 & 0.03 & 1.69 & 0.59 \\
\hline Hooded Crane & 19 & 13 & 0.05 & 0.02 & 0.96 & 0.43 \\
\hline Eurasian Crane & 18 & 19 & 0.08 & 0.09 & 1.10 & 1.21 \\
\hline
\end{tabular}


Table 3 The observed dietary niche overlap among the four crane species at Poyang Lake in the winters of 2017 and 2018. P (Obs $<=$ null) and $\mathrm{P}(\mathrm{Obs}>=$ null) indicate the tail probabilities for the observed index, which were lower and higher than the histogram of the simulated index, respectively. ${ }^{*}$ represents $P<0.05$, and ${ }^{* *}$ represents $P<0.01$

\begin{tabular}{lllll}
\hline Winter & & Observed niche overlap index & P (Obs $<=$ null) & P (Obs $>=$ null) \\
\hline 2017 & Siberian vs. White-naped & 0.21 & 0.819 & 0.181 \\
& Siberian vs. Hooded & 0.02 & 0.703 & 0.297 \\
Siberian vs. Eurasian & 0.16 & 0.900 & 0.100 \\
White-naped vs. Hooded & 0.49 & 0.952 & 0.048 \\
& White-naped vs. Eurasian & 0.35 & 0.895 & 0.106 \\
& Hooded vs. Eurasian & 0.35 & 0.919 & 0.081 \\
& Siberian vs. White-naped & 0.63 & 0.952 & $0.048^{*}$ \\
& Siberian vs. Hooded & 0.66 & 0.952 & $0.048^{*}$ \\
& Siberian vs. Eurasian & 0.62 & 0.950 & $0.049^{*}$ \\
& White-naped vs. Hooded & 0.99 & 0.997 & $0.003^{* *}$ \\
& White-naped vs. Eurasian & 0.89 & 0.987 & $0.013^{*}$ \\
& Hooded vs. Eurasian & 0.90 & 0.998 & $0.002^{* *}$ \\
\hline
\end{tabular}

that are overlooked by microhistological methods [67, 80]. It also enables the identification of food items at a higher taxonomic resolution $[69,81]$. However, we acknowledge that our study has two limitations. First, we used fecal samples as they are non-invasive. Nevertheless, fecal analysis is subjected to the biases caused by the differential digestive rates of food items $[82,83]$. Soft foods such as insect larvae tend to be under-represented in fecal samples because they are digested quickly and remain in gastro-intestinal tract for short periods, while hard foods such as mollusks tend to be over-represented because they break down slowly and remain in gastrointestinal tracts longer. Thus, food proportions in the feces may not correlate with food proportions ingested by cranes. In addition, some materials identified in the feces may be incidentally consumed by cranes and not really be used as food. Second, our study only considered the plant component of cranes' diets as plants were suggested to be their principal food types at Poyang Lake. Animal foods, consumed by the four crane species, but to a much lesser extent than plant foods [84-87], were not considered in our study.

The Siberian Crane is regarded as the most aquatic of all cranes, using wetlands for nesting, feeding and roosting $[49,88]$. The high dependence of the species on aquatic habitats was suggested to make it vulnerable to
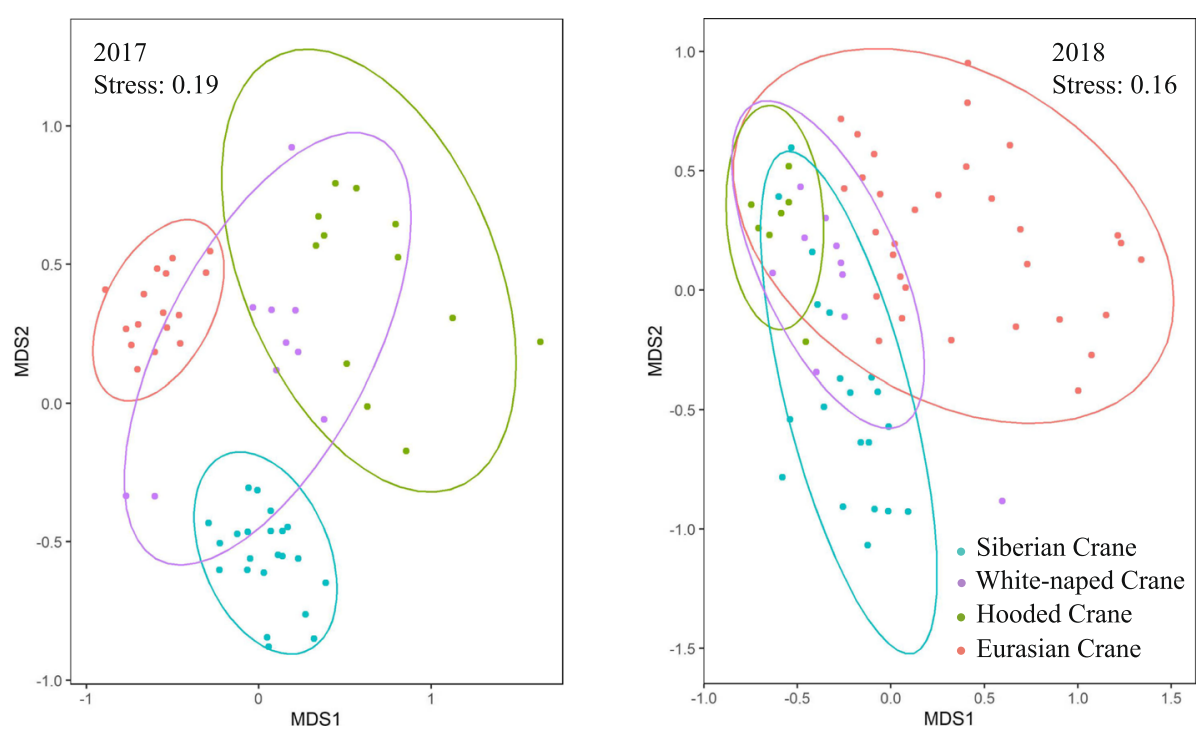

Fig. 4 The results of nonmetric multidimensional scaling ordination (NMDS) based on Bray-Curtis dissimilarity. The colors of the circles correspond to the crane species: blue: Siberian Crane; purple: White-naped Crane; green: Hooded Crane; and red: Eurasian Crane 
impacts of habitat degradation and to lead its classification as Critically Endangered [49]. At Poyang Lake, Siberian Cranes traditionally fed on tubers of Vallisneria, the dominant submerged macrophytes, in shallow waters and mudflats $[89,90]$. In winter 2010, due to a floodinduced Vallisneria tuber collapse, they were observed foraging for P. limprichtii taproots and T. edulis bulbs in grasslands for the first time [38, 44]. In the winters from 2015 to 2017, the diets of Siberian Cranes changed again, with thousands of cranes feeding on rice seeds and lotus rhizomes in agricultural habitats [61, 62, 64].

Our study identified 22 plant items in the feces of Siberian Cranes. These plant items were obtained from shallow waters, grasslands, and agricultural fields. Four plant items with yearly RRA $>10 \%$ were identified in the feces: Vallisneria tuber, $P$. criopolitanum rhizomes, rice seeds, and lotus rhizomes (the vegetative portions consumed by cranes were based on our field observation). Siberian Cranes' diet compositions showed substantial interannual variation. When the abundance of Vallisneria tubers was low (i.e., winter 2017), Siberian Cranes mainly fed on rice seeds, lotus rhizomes, and P. criopolitanum rhizomes in agricultural fields and grasslands. When the abundance of Vallisneria tubers was high (i.e., winter 2018), they mainly fed on Vallisneria tubers and P. criopolitanum rhizomes in shallow waters and grasslands. Our study, in combination with previous studies, indicates that the diets of $\mathrm{Si}$ berian Cranes have changed greatly since winter 2010 [38, 44, 62]. They have gradually broadened their dietary niches, which has probably been driven by the degradation of submerged plants [38, 44, 57].

Similar to Siberian Cranes, a diet shift was also observed in White-naped Cranes. Historically, Whitenaped Cranes only fed on submerged plants in shallow waters and mudflats of Poyang Lake [91]. Then, driven by the decline of submerged plants, they primarily fed at grasslands and mudflats [87, 91], consuming Vallisneria tuber, T. edulis, P. limprichtii, and Ranunculus polii [55, 87]. Our results indicate that, in addition to $T$. edulis and $P$. limprichtii that had previously been reported, the proportions of $P$. criopolitanum and Carex were also high in the feces. Hooded Cranes were suggested to mainly feed on the grassland plant $P$. limprichtii through direct observation [86]. Our study indicates that the grassland plants P. criopolitanum and Carex also occupied high proportions in the feces. The dominant food items in the feces of White-naped Cranes and Hooded Cranes varied greatly between the two winters. The variation in dietary composition indicated that the diversity and composition of the grassland plant community might have changed greatly between the two winters. The dietary niche overlap between White-naped Cranes and Hooded Cranes was the highest among the four crane species, aligning with their level of habitat niche overlap, which was also the highest among the species [92]. The high dietary and habitat niche overlaps suggest high competition potential between the two crane species.

The Eurasian Crane is a habitat generalist. It is known to feed in a variety of habitats including grasslands, mudflats, shallow waters, and agricultural fields [88, 92]. Its diet at Poyang Lake has not been documented previously. Our study indicates that P. criopolitanum, P. limprichtii, and rice were the dominant food items in the feces of Eurasian Cranes. The number of plant items consumed, dietary niche breadth, and Shannon-Wiener measures were the highest among the four crane species, supporting its generalist foraging strategy. In contrast to the three crane species above, Eurasian Cranes' diet compositions were similar between the two winters. Rice and grassland plants occupied high proportions in the feces in both winters.

\section{Important food resources for cranes}

Vallisneria tubers have been acknowledged as important food sources for cranes, especially Siberian Cranes and White-naped Cranes [55, 56]. Our study confirms the importance of Vallisneria tubers in the diet of Siberian Cranes. It was the most common food source in the feces of Siberian Cranes in winter 2018, when its abundance was high. Vallisneria tuber proportions in the feces of the three other crane species were not as high as that in the feces of Siberian Cranes, but it still occupied $5-9 \%$ of the total foods in winter 2018.

To our surprise, $P$. criopolitanum was found to be the first dominant food in the feces of White-naped Cranes, Hooded Cranes, and Eurasian Cranes, and the second dominant food in the feces of Siberian Cranes in winter 2018. In winter 2017, the proportions of P. criopolitanum were $<17 \%$ in the feces of Siberian Cranes and White-naped Cranes, and were $<3 \%$ in the feces of Hooded Cranes and Eurasian Cranes. The higher proportions of $P$. criopolitanum in winter 2018 than winter 2017 indicate that the abundance and availability of $P$. criopolitanum was much higher in winter 2018. P. criopolitanum is an annual grassland plant. It is sensitive to hydrological conditions and can only survive in a relatively narrow range of water depths and percent time inundated [93]. Due to the sensitivity, its distribution range and abundance showed high interannual variation $[94,95]$. Thus, it is likely that the abundance of $P$. criopolitanum was higher in winter 2018 than in winter 2017.

The importance of $P$. criopolitanum as a food source for the cranes at Poyang Lake has not been documented previously. It has only been suggested to be a major food source of Hooded Cranes at Shengin Lake, another lake in the middle and lower Yangtze River floodplain [86, 
96]. P. criopolitanum is a dominant wetland plant at Poyang Lake [93, 97]. The coverage percentage of this plant is the third highest among grassland plants, accounting for $12 \%$ of the total areas of grasslands [97]. This plant species is usually distributed at elevations of 9-12 m above sea level near mudflats and shallow waters [97], which are frequently used by cranes. Its rhizome, with a shallow burial depth, is high in energy and nutritional content and low in crude fibre $[38,86]$. All these characteristics make $P$. criopolitanum rhizome a potentially important food source for cranes. We frequently observed cranes dig and feed on rhizomes of $P$. criopolitanum and leave aboveground parts in the fields. Therefore, we believe that $P$. criopolitanum was used as food, not incidentally consumed by cranes. However, we need to be caution that high proportion of $P$. criopolitanum in the feces does not mean high proportion in the diets. More work on the importance of $P$. criopolitanum in the diets of cranes is needed.

\section{The roles of agricultural fields in crane protection}

With the loss and degradation of natural wetlands, the roles of artificial wetlands in waterbird protection have been under intensive debate [98, 99]. Although agricultural fields cannot completely replace the function of natural wetlands as waterbird habitats [100-102], agricultural fields might provide alternative or complementary habitats for waterbirds in all life stages $[38,103$, 104]. The proportions of domesticated species in the feces of Siberian Cranes varied considerably between years. In winter 2017, when the abundance of Vallisneria tubers was low, the proportion of Vallisneria in Siberian Cranes' feces was only $0.95 \%$. Siberian Cranes may not have found enough foods in the shallow waters and mudflats and were forced to search for rice seeds and lotus rhizomes in agricultural fields. In winter 2018, when the abundance of Vallisneria tubers rebounded, Siberian Cranes moved back to shallow waters and mudflats, and a large proportion of their traditional food $\mathrm{Val}$ lisneria tubers, and also P. criopolitanum were detected in the feces. A similar abandonment of tuber foraging occurred following the tuber collapse in 2010 and then resumed in the next winter when tubers rebounded in $2011[38,44]$. The diet and habitat changes indicate that agricultural habitats were important refuges for Siberian Cranes, providing important food resources for them to survive through winters with few Vallisneria tubers. They also indicate that Siberian Cranes prefer natural wetlands to agricultural fields [38].

Similar to Siberian Cranes, White-naped Cranes and Hooded Cranes consumed rice seeds and lotus rhizomes in winter 2017 but did not consume any in winter 2018 . The changes in the proportions suggest that the abundance of food resources in natural wetlands might have been low in winter 2017. The deficient food resources might have been Vallisneria tubers, but might also have been grassland plants, the primary food sources of these two crane species. Under natural food shortage conditions (i.e., winter 2017), White-naped Cranes and Hooded Cranes utilized agricultural fields. When the abundance of Vallisneria tubers and probably grassland plants were high (i.e., winter 2018), the two crane species returned to their natural habitats. Therefore, for Whitenaped Cranes and Hooded Cranes, agricultural fields were important alternative foraging habitats used as buffers against starvation during periods of natural food shortages. The return of the two crane species to natural wetlands in winter 2018 further emphasizes the superior quality of natural habitats over agricultural fields as foraging habitats for cranes [38].

The proportions of rice seeds in the feces of Eurasian Cranes were high in the two winters, though the proportion in winter 2017 was twice as high as that in winter 2018. Therefore, agricultural fields appeared to be consistently important as foraging habitats for Eurasian Cranes. The frequent use of agricultural fields by Eurasian Cranes has been documented widely $[49,105,106]$.

Domesticated species generally contain high energy and nutritional content and are of superior quality compared to natural plants [86, 104]. Farmland foraging has been suggested to contribute to increase in the abundance of some goose [107], egret [108] and wader [109] populations in Japan, Korea, Europe, and North America. However, cranes generally avoid human disturbance when select foraging sites $[110,111]$. Human disturbance in agricultural fields around Poyang Lake is considerably high due to intensive agricultural activity [112]. High human disturbance was suggested to be a major reason that wintering geese were almost confined within natural wetlands and hesitated to exploit the riches of the modern agricultural habitats at Poyang Lake [112, 113]. High human disturbance also resulted in Siberian Cranes spending twice as much time alerting in agricultural fields than they did in natural habitats [114]. The high level of human disturbance in agricultural fields might contribute to the preference for natural wetlands by Siberian Cranes, White-naped Cranes and Hooded Cranes at Poyang Lake. Moreover, although agriculture fields contain energy-rich crops, wetlands contain diverse food resources, especially protein-rich invertebrates, which might better satisfy dietary needs of cranes $[110,115]$. Taken together, security and diverse food resources might have attracted cranes to select wetlands as foraging sites.

Submerged macrophytes at Poyang Lake have degraded in recent decades [57-60], and Vallisneria tuber disappearance is expected to occur more frequently 
under future climate change [57, 60]. Cranes may increasingly depend upon agricultural fields around Poyang Lake, which may, in turn, cause significant crop damage and economic losses. This is especially true on agricultural fields surrounding protected wetlands where waterbirds concentrate in high numbers [116, 117]. At Poyang Lake, cranes mainly fed on post-harvest remains of rice seeds and lotus rhizomes; thus, crop damage and economic loss were limited. However, we observed some farmers scared cranes away from their agricultural fields. There were more than 14 million free-ranging poultry raised at agricultural fields around Poyang Lake [118], where they gleaned waste grain residues in stubble fields. Crane feeding would reduce the food abundance of the free-ranging domestic poultry; thus, farmers drove cranes away. To reduce human disturbance, environmental education is needed because farmers are more likely to protect cranes if they understand the endangered degree and the ecological significance of cranes.

\section{Effects of tuber collapse on dietary niche breadth and overlap among crane species}

Vallisneria tuber is an important food source for Siberian Cranes (89, 90, this study); thus, variation in its abundance might influence Siberian Cranes' dietary niche breadth. The numbers of food items, dietary niche breadth and Shannon-Wiener measures of Siberian Cranes were similar between winter 2017 and winter 2018. This is inconsistent with the contention that during seasons with a low abundance of dominant food, the dietary niche may broaden as consumers relying on insufficient preferred food items are forced to add less profitable resources to their diets $[26,119,120]$. In winter 2017, with low Vallisneria tuber abundance, Siberian Cranes left shallow waters and mudflats and moved to rice paddies and lotus ponds [61, 62, 64]. Their foods changed from Vallisneria tuber to rice seeds and lotus rhizomes almost completely. As the energy, protein and fat contents of crops are generally as good as or superior to natural foods and are often present in agricultural fields in far greater abundance [86, 104], Siberian Cranes may gain enough energy through feeding on crops and do not need to add many other food sources. Moreover, the Siberian Crane is a dietary specialist $[89,90]$. Poyang Lake has a relatively simple plant community composition, with Vallisneria and Hydrilla verticillate being the dominant submerged macrophytes [59] and Carex being the dominant grassland plants [121]. Therefore, there may be few options for Siberian Cranes, which might lead to the failure of this species to widen its dietary niche breadth.

In contrast to Siberian Cranes, the numbers of food items, dietary niche breadths and Shannon-Wiener measures of White-naped Cranes and Hooded Cranes were higher in winter 2017 than in winter 2018. P. criopolitanum was the predominant food item in the feces of the two crane species in winter 2018, and the proportions of Vallisneria tubers were also high. The abundances of Vallisneria tubers and probably P. criopolitanum at Poyang Lake declined greatly in winter 2017. When there is a short-fall in food availability, animals may optimize foraging behavior and increase their dietary breath [122, 123]. The short-fall in the abundances of $P$. criopolitanum and Vallisneria tubers in winter 2017 might have driven the two crane species to add less profitable grassland plants in their diets. Although the two cranes also consumed high-quality rice seeds and lotus rhizomes in winter 2017, their proportions were low in the feces and these foods might be unable to meet the energy requirements of the two crane species. The niche expansion of the two crane species during periods of preferred food shortage was in agreement with the basic prediction of optimal foraging theory [22, 23]. It is also consistent with a commonly observed fact that energy-maximizing models work better when animals food-limited [124].

The dietary niche overlaps among the crane species were low in winter 2017, with the four crane species diverging in their principal food items. However, in winter 2018, the niche overlaps were significantly higher than expected by chance. They had similar diet compositions, with $P$. criopolitanum rhizomes and Vallisneria tubers being the principal food items in the feces. The increased overlap might have been caused by the high abundances of the two plant species in winter 2018, which allowed the four crane species to share the same food items with low interspecific competition. Our study is consistent with previous research that suggested that among-species dietary niches tended to overlap more during seasons of high food abundance [32, 33, 125, $126]$. Greater resource availability could promote an increase in species utilization of similar resources and reduce competitive interactions between species [32, 34, 126]. By contrast, during seasons with low food abundance, species may partition limited food resources to decrease interspecific competition, leading to a decrease in niche overlap $[126,127]$. It has been suggested that diet partitioning facilitates the coexistence of many closely related species $[7,128]$. The interannual variation in niche overlap observed in our study suggests that diet partitioning may be restricted to specific temporal cases. In seasons or years with abundant food sources, interspecific competition may be relaxed and niche overlap could be high.

\section{Conclusions}

In summary, by using metabarcoding technology, our study gained new insights into cranes' diets that are essential for informing habitat management to improve 
the availability of foraging resources. Vallisneria tubers was confirmed as an important food source of cranes. Surprisingly, P. criopolitanum also occupied high proportions in the feces of cranes and may also be important. Our study emphasizes the superior quality of natural wetlands compared to agricultural fields as foraging habitats for cranes. The recent degradation of submerged macrophytes at Poyang Lake potentially threatens the survival of cranes, especially Siberian Cranes. Therefore, it is urgent to reverse the broad decline of submerged macrophytes and provide important foraging habitats for cranes during years of tuber collapses. The abundances of Vallisneria tubers, and probably P. criopolitanum, at Poyang Lake greatly influenced the dietary niche width and overlaps among crane species. Cranes exhibited low dietary niche overlap during periods of preferred food shortage but significantly high overlap during periods when preferred foods were plentiful. While high niche overlap is often interpreted as intense interspecific competition, our study highlights the importance of taking food abundance into account.

\section{Materials and methods}

\section{Study areas}

Poyang Lake, the largest freshwater lake in China, is one of the most important wintering areas for waterbirds along the East Asian-Australasian Flyway (Fig. 1) [51, 129]. It is characterized by dramatic seasonal hydrological fluctuations, with an average change of $9.24 \mathrm{~m}$ between the summer high and winter low water levels [130]. During summer, the inundation area is $>2500$ $\mathrm{km}^{2}$ [131]. In autumn and winter, the water level drops, causing the inundation area to shrink to $<1000 \mathrm{~km}^{2}$ [131]. Poyang Lake contains 102 sublakes, which are inundated and integrated with the main body of Poyang Lake during summer and are isolated during winter [132]. As the water level drops, the sublakes appear, and large areas of grasslands, mudflats, and shallow water areas are exposed, providing winter foraging and roosting areas for approximately 420,000 waterbirds from approximately 111 species [133, 134].

\section{Vallisneria tuber survey}

The density and biomass of Vallisneria tubers were surveyed at three sublakes (Dahuchi, Shahu, and Changhuchi; Fig. 1) of Poyang Lake in late October and early November of 2017 and 2018 before large numbers of wintering waterbirds arrived. We set 76, 183, and 36 sampling plots uniformly located at Dahuchi, Shahu, and Changhuchi, respectively. Vallisneria tubers were collected from two quadrats in each plot with a locally made steel grab sampler. The sampler has two long handles. At the end of the handles, there are two scoops facing each other. The sampler was inserted into the substrate and the scoops brought together to collect about $15 \mathrm{~cm}$ long $\times 13 \mathrm{~cm}$ wide $\times 30 \mathrm{~cm}$ high sample of substrate. Tubers were subsequently cleaned and counted. The dry weight of tubers in each quadrat was weighed after oven-drying at $80^{\circ} \mathrm{C}$ until constant weight. The tuber density and biomass in each plot was calculated by dividing total tuber number and tuber mass across two quadrats by quadrat area, respectively. We used t-test to explore whether the tuber density and biomass in the winters of 2017 and 2018 significantly deviated from the historical average values in the winters from 1999 to 2016 [57]. The historical tuber density and biomass data were collected by the Poyang Lake National Nature Reserve at three sublakes (Dahuchi, Shahu, and Meixihu) [57]. $\mathrm{R} 3.6 .0$ was used to do the t-test analyses.

\section{Fecal sample collection}

Fecal samples were collected at Poyang Lake in the winters of 2017 and 2018. We first investigated the distributions of cranes. When we saw foraging cranes, we waited until they left to avoid disturbing them. Soon after they left, we went to the foraging sites to collect fresh feces (i.e., feces with wet surface) with sterilized tweezers. To minimize the probability of multiple samples from the same individual, all collected samples were separated by at least $5 \mathrm{~m}$. We stored the samples in liquid nitrogen in the field and transferred them to $\mathrm{a}-80^{\circ} \mathrm{C}$ refrigerator for long-term storage in the laboratory. To ensure that the sources of the feces were known, we tried to collect samples from monospecific flocks. For samples collected from mixed-species flocks, we used DNA analysis to identify the species that deposited the fecal samples. Plants were also collected in the field to construct a DNA barcoding reference database.

\section{Species identification}

Because of the similar morphologies of the feces of the four crane species, we used DNA analysis to identify the species that deposited the fecal samples collected from mixed-species flocks. For the genetic species assignment of each fecal sample, we scraped the external surface, which contain DNA from the host species as a result of the sloughing of cells from the digestive tract. DNA was extracted with the QIAamp Power Fecal DNA Kit (Qiagen, USA) according to the manufacturer's guidelines. For each round of DNA extraction, negative controls (i.e., extraction without feces) were included to monitor for possible contamination. We amplified the mitochondrial DNA D-loop fragment with the primer pair DL02F 
(5'-3' GCGGCCCGAAAAGCCGCTG) and DL02R (5'3' GCCCTGACATAGGAACCAGAGGCGC) [135]. PCR amplifications were carried out in a total volume of $25 \mu \mathrm{l}$ containing $12.5 \mu \mathrm{l} \mathrm{PCR} \mathrm{mix} \mathrm{(Tiangen,} \mathrm{Beijing,}$ China), $1 \mu \mathrm{l}$ DNA, $1 \mu \mathrm{l}$ each primer, and $9.5 \mu \mathrm{l} \mathrm{H}_{2} \mathrm{O}$. The reaction conditions were as follows: denaturation at $94{ }^{\circ} \mathrm{C}$ for $4 \mathrm{~min}$, followed by 34 cycles at $94{ }^{\circ} \mathrm{C}$ for $48 \mathrm{~s}$, $56^{\circ} \mathrm{C}$ for $48 \mathrm{~s}$, and $72{ }^{\circ} \mathrm{C}$ for $1 \mathrm{~min}$, and a final $10 \mathrm{~min}$ at $72^{\circ} \mathrm{C}$. We checked for the presence of a PCR product of suitable length by electrophoresis on a $1 \%$ agarose gel. Sequencing was carried out on an ABI 3730xl analyzer by Sangon Biotech (Shanghai, China). The complete sequences were assembled using Seqman II (DNASTAR) and compared visually to the original chromatograms to avoid reading errors. The taxonomic assignment was conducted by searching against the nucleotide database of GenBank using Web BLAST.

\section{Construction of a barcode reference database}

We downloaded the trnL sequences of 48 plant species commonly seen at Poyang Lake from GenBank. For the plant species not included in GenBank, we sequenced trnL by ourselves. Total DNA was extracted using the hexadecyltrimethylammonium bromide (CTAB) protocol. We used primer pair $c\left(5^{\prime}-3^{\prime}\right.$ CGAAATCGGT AGACGCTACG) and $h\left(5^{\prime}-3^{\prime}\right.$ CCATTGAGTCTCTG CACCTATC) to amplify an approximately $150 \mathrm{bp}$ region of the chloroplast trnL intron [136]. This primer pair was chosen as it can amplify DNA from a wide range of wetland plants [70]. PCR amplifications were carried out in a total volume of $25 \mu \mathrm{l}$ containing $12.5 \mu \mathrm{l} \mathrm{PCR} \mathrm{mix}$ (Tiangen, Beijing, China), $1 \mu \mathrm{l}$ DNA, $1 \mu \mathrm{l}$ each primer, and $9.5 \mu \mathrm{H}_{2} \mathrm{O}$. The reaction conditions were as follows: denaturation at $94{ }^{\circ} \mathrm{C}$ for $4 \mathrm{~min}$, followed by 35 cycles at $94{ }^{\circ} \mathrm{C}$ for $30 \mathrm{~s}, 56^{\circ} \mathrm{C}$ for $30 \mathrm{~s}$, and $72{ }^{\circ} \mathrm{C}$ for $45 \mathrm{~s}$, and a final $10 \mathrm{~min}$ at $72^{\circ} \mathrm{C}$. We used electrophoresis to check the PCR products, ABI 3730xl analyzer to perform sequencing, and Seqman II to assemble the sequences.

\section{DNA extraction and high-throughput sequencing of fecal samples}

To uncover plant component consumed by cranes, a modified CTAB protocol [70] was used to extract the DNA from approximately $200 \mathrm{mg}$ of the interior of each fecal sample. DNA extraction was conducted in a dedicated laboratory for analyses of DNA from samples with low DNA quality. For each batch of DNA extraction, negative controls were included to monitor for possible contamination. The primers $c$ and $h$ with a $6 \mathrm{bp}$ tag added to $5^{\prime}$ ends of each primer were used to amplify $\operatorname{trn} \mathrm{L}$ gene. The PCR amplification procedure was the same as barcode database construction. For each sample, a unique combination of tags in the forward and reverse primers was used so that sample-specific data can be recovered after sequencing. Three PCR replicates were performed for each sample to reduce amplification bias. The three replicates were pooled, and the DNA concentration and purity were monitored on a $1 \%$ agarose gel. Only samples with a clear band were processed further. Samples were purified using the SanPrep Column PCR Product Purification Kit (Sangon Biotech, Shanghai, China). The purified PCR products were pooled, taking into account of DNA concentration to obtain an approximately equal amount of amplicon DNA from each fecal sample. The pool of individually tagged amplicons was used to prepare a sequencing library using the TruSeq DNA PCR-Free Sample Preparation Kit (Illumina, USA) following manufacturer's recommendations. The library was sequenced on an Illumina HiSeq 2500 platform, and $250 \mathrm{bp}$ paired-end reads were generated. Library preparation and sequencing were conducted by Novogene (Beijing, China).

\section{Sequencing data analysis}

After high-throughput sequencing, the paired-end reads were demultiplexed into sample-specific files based on their unique tags. The tags and primer sequences were subsequently trimmed. The paired-end reads were merged using FLASH 1.2.7 [137] and then filtered using QIIME 1.7.0 [138]. Sequences were dereplicated and clustered to OTUs using USEARCH 11.0.667 [139] at the similarity threshold of $97 \%$. All OTUs were assigned to taxonomic units by referring to the local plant database using blast 2.2.31+, with thresholds of identity > $97 \%$ and e-value $<1.0 \mathrm{e}^{-50}$. If an OTU matched two or more taxa, it was assigned to a higher taxonomic level that included all taxa.

To evaluate the sufficiency of sequencing depth and sampling size, individual-, species-, and sample-based rarefaction curves were built using EstimateS 8.2 [140]. The curves were computed by randomly resampling sequences or samples and plotting these against the numbers of OTUs. The read abundance data were converted to RRA of each food item using the following equation [79]:

$$
\mathrm{RRA}=\frac{1}{\mathrm{~S}} \sum_{\mathrm{K}=1}^{\mathrm{S}} \frac{\mathrm{n}_{\mathrm{i}, \mathrm{k}}}{\sum_{\mathrm{i}=1}^{\mathrm{T}} \mathrm{n}_{\mathrm{i}, \mathrm{k}}} \times 100 \%
$$

where $n_{i, k}$ is the number of sequences of food item $i$ in sample $k, T$ is the total number of food items, and $S$ is the sampling size.

\section{Dietary niche breadth and overlap among crane species}

To explore whether the cranes' diets showed substantial interannual variation, we calculated Pearson correlations between diet compositions of each crane species in winter 2017 and winter 2018. The proportion of each food 
item in each sample was used as input file. The Shannon-Wiener diversity index $\left(\mathrm{H}^{\prime}\right)$ was calculated to explore the diet diversity of each crane species. The following equations were used:

$$
H^{\prime}=-\sum_{i=1}^{s} P_{i} \ln P_{i}
$$

where $P_{i}$ is the proportion of food item i out of all foods and $S$ is the total number of food items. The dietary breadth (B) was measured using Levins' index [141], according to the following formula:

$$
\mathrm{B}=1 / \sum_{\mathrm{i}=1}^{\mathrm{s}} \mathrm{P}_{\mathrm{i}}^{2},
$$

Hurlbert's formula [142] was applied to standardize the trophic niche measure, according to the following formula:

$$
\mathrm{B}_{\mathrm{a}}=(\mathrm{B}-1) /(\mathrm{S}-1),
$$

where $B$ is the Levins index of niche breadth and $S$ is the total number of prey categories. $B_{a}$ values range between 0 (minimum diet breadth) and 1 (maximum diet breadth).

The dietary overlap of each species pair $\left(\mathrm{Q}_{\mathrm{jk}}\right)$ was calculated using Pianka's index [143], according to the following formula:

$$
\mathrm{Q}_{\mathrm{jk}}=\frac{\sum_{\mathrm{i}=1}^{\mathrm{s}} \mathrm{P}_{\mathrm{ij}} \mathrm{P}_{\mathrm{ik}}}{\sqrt{\sum_{\mathrm{i}=1}^{\mathrm{s}} \mathrm{P}_{\mathrm{ij}}^{2} \sum_{\mathrm{i}=1}^{\mathrm{s}} \mathrm{P}_{\mathrm{ik}}^{2}}}
$$

where $Q_{j k}$ is Pianka's niche overlap index between species $j$ and species $k$; $P_{i j}$ is the proportion of resource $i$ out of all resources used by species j; and $\mathrm{P}_{\mathrm{ik}}$ is the proportion of resource $i$ out of all resources used by species k. $Q_{j k}$ ranges from 0 , where two species have no food items in common, to 1 , where there is complete overlap in resource use.

We tested whether the observed niche overlap differed from what would be expected by chance using the program EcoSim 1.00 [144]. Null models were calculated based on the randomization algorithm RA3 and 1000 simulated resource utilization matrices were generated to compare with observed resource utilization data.

Patterns of diet composition and overlap of the four crane species were visualized in two-dimensional space using the NMDS plots. We performed NMDS analysis based on the Bray-Curtis dissimilarity. The read abundance of each food item in each sample was used as the input file. The R package "Vegan" [145] was used for the NMDS analysis, and "ggplots" [146] was used to create graphics.

\section{Abbreviations}

NMDS: Nonmetric multidimensional scaling; OTU: Operational taxonomy units; RRA: Relative read abundance

\section{Supplementary Information}

The online version contains supplementary material available at https://doi. org/10.1186/s12983-021-00411-2.

Additional file 1: Table S1. Sampling site information. Table S2. Relative read abundance (RRA; \%) of each food item in the diets of Siberian Cranes, White-naped Cranes, Hooded Cranes, and Eurasian Cranes in the winters of 2017 and 2018. Figure S1. Rarefaction curve of each crane species.

\section{Acknowledgements}

We thank Lanhua Wang, Haiyan Zhou, Xiaolong Wang, the Poyang Lake National Nature Reserve, and the Nanji Wetland National Nature Reserve for assisting in sample collection. We thank Zhichun Lan, James Burnham, and Chunlan Zhang for helping data analyses. We also thank Jeb Barzen from Private Lands Conservation, Andrew J. Caven from Crane Trust and an anonymous reviewer for reviewing our manuscript and giving valuable comments and suggestions.

\section{Authors' contributions}

$\mathrm{JH}$ collected fecal samples, performed the experiments, and analyzed the data. LL conducted tuber surveys. YW collected fecal samples and performed the experiments. WW conceived the study, collected fecal samples, analyzed the data, and wrote the original draft. $H Z$, ND and PL revised the manuscript. All authors read and approved the final manuscript.

\section{Funding}

This work was supported by the National Natural Science Foundation of China (No. 31772480), the Natural Science Foundation of Jiangxi Province (No. 20181BAB214007), and Funding Project of Jiangxi Academy of Sciences (No. 2020-YGY-01)

\section{Availability of data and materials}

The datasets used and/or analyzed during the current study are available from the corresponding authors on reasonable request.

\section{Declarations}

Ethics approval and consent to participate

Our study collected bird fecal samples using a non-invasive method. Our fieldwork was permitted by the Poyang Lake National Nature Reserve and the Nanji Wetland National Nature Reserve.

\section{Consent for publication}

Not applicable.

\section{Competing interests}

The authors declare they have no competing interests.

\section{Author details}

1Jiangxi Province Key Laboratory of Watershed Ecosystem Change and Biodiversity, Center for Watershed Ecology, Institute of Life Science and School of Life Science, Nanchang University, Nanchang 330031, China. ${ }^{2}$ Key Laboratory of Poyang Lake Environment and Resource Utilization, Ministry of Education, Nanchang University, Nanchang 330031, China. Jiangxi Poyang Lake Wetland Conservation and Restoration National Permanent Scientific Research Base, National Ecosystem Research Station of Jiangxi Poyang Lake Wetland, Nanchang 330031, China. ${ }^{4}$ Jiangxi Poyang Lake National Nature Reserve Authority, Nanchang 330038, China. ${ }^{5}$ The Institute of Biology and Resources, Jiangxi Academy of Sciences, Nanchang 330096, China. 


\section{Received: 1 April 2020 Accepted: 29 April 2021}

\section{Published online: 17 May 2021}

\section{References}

1. Schoener TW. Resource partitioning in ecological communities. Science. 1974;185(4145):27-39. https://doi.org/10.1126/science.185.4145.27.

2. Hutchinson GE. Homage to Santa Rosalia or why are there so many kinds of animals? Am Nat. 1959;93(870):145-59. https://doi.org/10.1086/282070.

3. Arthur W. The niche in competition and evolution. New York: Wiley; 1987

4. Sorensen MFL. Niche shifts of coal tits Parus ater in Denmark. J Avian Biol. 1997;28(1):68-72. https://doi.org/10.2307/3677096.

5. Aguiar CM, Santos GMdM, Martins CF, Presley SJ. Trophic niche breadth and niche overlap in a guild of flower-visiting bees in a Brazilian dry forest. Apidologie. 2013;44(2):153-62. https://doi.org/10.1007/s13592-012-0167-4.

6. Leray M, Alldredge AL, Yang JY, Meyer CP, Holbrook SJ, Schmitt RJ, et al. Dietary partitioning promotes the coexistence of planktivorous species on coral reefs. Mol Ecol. 2019;28(10):2694-710. https://doi.org/10.1111/mec.1 5090 .

7. Luiselli L. Resource partitioning and interspecific competition in snakes: the search for general geographical and guild patterns. Oikos. 2006;114(2):193211. https://doi.org/10.1111/j.2006.0030-1299.14064.x

8. Herrera LG, Hobson KA, Rodríguez M, Hernandez P. Trophic partitioning in tropical rain forest birds: insights from stable isotope analysis. Oecologia. 2003;136(3):439-44. https://doi.org/10.1007/s00442-003-1293-5.

9. Kartzinel TR, Chen PA, Coverdale TC, Erickson DL, Kress WJ, Kuzmina ML, et al. DNA metabarcoding illuminates dietary niche partitioning by African large herbivores. P Nat Acad Sci USA. 2015;112(26):8019-24. https://doi. org/10.1073/pnas.1503283112.

10. Alatalo RV. Seasonal dynamics of resource partitioning among foliagegleaning passerines in northern Finland. Oecologia. 1980;45(2):190-6. https://doi.org/10.1007/BF00346459.

11. Martins RC, Catry T, Santos CD, Palmeirim JM, Granadeiro JP. Seasonal variations in the diet and foraging behaviour of dunlins Calidris alpina in a south European estuary: improved feeding conditions for northward migrants. PLoS One. 2013;8(12):e81174. https://doi.org/10.1371/journal.pone. 0081174.

12. Preston CR, Jones RE, Horton NS. Golden eagle diet breadth and reproduction in relation to fluctuations in primary prey abundance in Wyoming's Bighorn Basin. J Raptor Res. 2017:51(3):334-46. https://doi.org/1 0.3356/JRR-16-39.1.

13. Isacch JP, Darrieu CA, Martinez MM. Food abundance and dietary relationships among migratory shorebirds using grasslands during the nonbreeding season. Waterbirds. 2005;28(2):238-45. https://doi.org/10.1675/1 524-4695(2005)028[0238:FAADRA]2.0.CO:2

14. Piersma T, Degoeij P, Tulp I. An evaluation of intertidal feeding habitats from a shorebird perspective: towards relevant comparisons between temperate and tropical mudflats. Netherlands J Sea Res. 1993;31(4):503-12. https://doi.org/10.1016/0077-7579(93)90062-W.

15. Quinn JT, Hamilton DJ. Variation in diet of Semipalmated sandpipers (Calidris pusilla) during stopover in the upper bay of Fundy, Canada. Can J Zool. 2012;90(9):1181-90. https://doi.org/10.1139/z2012-086.

16. MacDonald EC, Ginn MG, Hamilton DJ. Variability in foraging behavior and implications for diet breadth among Semipalmated sandpipers staging in the upper bay of Fundy. Condor. 2012;114:135-44.

17. Wei Z, Zheng M, Zhou L, Xu W. Flexible foraging response of wintering hooded cranes (Grus monacha) to food availability in the lakes of the Yangtze River floodplain, China. Animals. 2020;10(4):568. https://doi.org/1 0.3390/ani10040568

18. Dong HY, Lu GY, Zhong XY, Yang XJ. Winter diet and food selection of the black-necked crane Grus nigricollis in Dashanbao, Yunnan, China. PeerJ. 2016:4:e1968. https://doi.org/10.7717/peerj.1968.

19. Baker AJ, Gonzalez PM, Piersma T, Niles LJ, do Nascimento IDS, Atkinson PW, et al. Rapid population decline in red knots: fitness consequences of decreased refuelling rates and late arrival in Delaware Bay. P Roy Soc B Bio. 2004;271:875-82

20. MacArthur RH, Pianka ER. On optimal use of a patchy environment. Am Nat. 1966;100(916):603-9. https://doi.org/10.1086/282454.

21. Pyke GH. Optimal foraging theory: a critical review. Annu Rev Ecol Syst. 1984;15(1):523-75. https://doi.org/10.1146/annurev.es.15.110184.002515.

22. Schoener TW. Theory of feeding strategies. Annu Rev Ecol Syst. 1971;2(1): 369-404. https://doi.org/10.1146/annurev.es.02.110171.002101.
23. Pulliam HR. On the theory of optimal diets. Am Nat. 1974;108(959):59-74. https://doi.org/10.1086/282885.

24. Zhang S, Ma Z, Choi C, Peng H, Melville DS, Zhao T, et al. Morphological and digestive adjustments buffer performance: how staging shorebirds cope with severe food declines. Ecol Evol. 2019;9(7):3868-78. https://doi. org/10.1002/ece3.5013.

25. Baker MC, Baker AE. Niche relationships among six species of shorebirds on their wintering and breeding ranges. Ecol Monogr. 1973;43(2):193-212. https://doi.org/10.2307/1942194.

26. Salinas-Ramos VB, Montalvo LGH, León-Regagnon V, Arrizabalaga-Escudero A, Clare EL. Dietary overlap and seasonality in three species of mormoopid bats from a tropical dry forest. Mol Ecol. 2015;24(20):5296-307. https://doi. org/10.1111/mec.13386.

27. Clare EL, Symondson WO, Fenton MB. An inordinate fondness for beetles? Variation in seasonal dietary preferences of night-roosting big brown bats (Eptesicus fuscus). Mol Ecol. 2014;23(15):3633-47. https://doi.org/10.1111/ mec.12519.

28. Layman CA, Quattrochi JP, Peyer CM, Allgeier JE. Niche width collapse in a resilient top predator following ecosystem fragmentation. Ecol Lett. 2007;10(10):937-44. https://doi.org/10.1111/ j.1461-0248.2007.01087.x.

29. Lesser JS, James WR, Stallings CD, Wilson RM, Nelson JA. Trophic niche size and overlap decreases with increasing ecosystem productivity. Oikos. 2020; 129(9):1303-13. https://doi.org/10.1111/oik.07026.

30. Calizza E, Costantini ML, Careddu G, Rossi L. Effect of habitat degradation on competition, carrying capacity, and species assemblage stability. Ecol Evol. 2017;7(15):5784-96. https://doi.org/10.1002/ece3.2977.

31. Calizza E, Careddu G, Caputi SS, Rossi L, Costantini ML. Time- and depthwise trophic niche shifts in Antarctic benthos. PLoS One. 2018;13(3): e0194796. https://doi.org/10.1371/journal.pone.0194796.

32. Pool T, Holtgrieve G, Elliott V, McCann K, McMeans B, Rooney N, et al. Seasonal increases in fish trophic niche plasticity within a flood-pulse river ecosystem (Tonle Sap Lake, Cambodia). Ecosphere. 2017;8(7):e01881. https:// doi.org/10.1002/ecs2.1881.

33. Soininen EM, Gauthier G, Bilodeau F, Berteaux D, Gielly L, Taberlet P, et al. Highly overlapping winter diet in two sympatric lemming species revealed by DNA metabarcoding. PLoS One. 2015;10(1):e0115335. https://doi.org/1 0.1371/journal.pone.0115335.

34. Novcic I. Weak niche partitioning by migrating shorebirds in a single-foodtype environment. Avian Biol Res. 2019;12(3):109-17. https://doi.org/10.11 $77 / 1758155919841279$

35. Forero MG, Bortolotti GR, Hobson KA, Donazar JA, Bertelloti M, Blanco G. High trophic overlap within the seabird community of Argentinean Patagonia: a multiscale approach. J Anim Ecol. 2004;73(4):789-801. https:// doi.org/10.1111/j.0021-8790.2004.00852.x.

36. Wegge P, Kastdalen L. Habitat and diet of young grouse broods: resource partitioning between Capercaillie (Tetrao urogallus) and black grouse (Tetrao tetrix) in boreal forests. J Ornithol. 2008;149(2):237. https://doi.org/10.1007/s1 0336-007-0265-7.

37. Jaeger A, Connan M, Richard P, Cherel Y. Use of stable isotopes to quantify seasonal changes of trophic niche and levels of population and individual specialisation in seabirds. Mar Ecol Prog Ser. 2010;401:269-77. https://doi. org/10.3354/meps08380.

38. Burnham J, Barzen J, Pidgeon AM, Sun B, Wu J, Liu G, et al. Novel foraging by wintering Siberian cranes Leucogeranus leucogeranus at China's Poyang Lake indicates broader changes in the ecosystem and raises new challenges for a critically endangered species. Bird Conserv Int. 2017;27(2):204-23. https://doi.org/10.1017/S0959270916000150.

39. Chiu MC, Kuo MH, Sun YH, Hong SY, Kuo HC. Effects of flooding on avian top-predators and their invertebrate prey in a monsoonal Taiwan stream. Freshw Biol. 2008;3:1335-44.

40. Hansen BB, Aanes R, Sæther B-E. Feeding-crater selection by high-arctic reindeer facing ice-blocked pastures. Can J Zool. 2010;88(2):170-7. https:// doi.org/10.1139/Z09-130

41. Xu W, Hu W, Deng J, Zhu J, Zhou N, Liu X. Impacts of water depth and substrate type on Vallisneria natans at wave-exposed and sheltered sites in a eutrophic large lake. Ecol Eng. 2016;97:344-54. https://doi.org/10.1016/j. ecoleng.2016.10.029.

42. Li W, Liu G, Xiong B, Pu Y. The restoration of aquatic vegetation in lakes of Poyang Lake nature reserve after catastrophic flooding 1998. J Wuhan Bot Res. 2004;22:301-6. 
43. Wu G, de Leeuw J, Barzen J, Venus V, Burnham J, Liu Y, et al. In: Li W, editor A conceptual framework to integrate a simulation model of plant biomass for Vallisneria spiralis L. with remote sensing and a geographical information system. In: wetland and water resource modeling and assessment: a watershed perspective. Boca Raton: CRC Press; 2008.

44. Jia Y, Jiao S, Zhang Y, Zhou Y, Lei G, Liu G. Diet shift and its impact on foraging behavior of Siberian crane (Grus leucogeranus) in Poyang Lake. PLoS One. 2013;8(6):e65843. https://doi.org/10.1371/journal.pone.0065843.

45. Fox AD, Cao L, Zhang Y, Barter M, Zhao MJ, Meng FJ, et al. Declines in the tuber-feeding waterbird guild at Shengjin Lake National Nature Reserve, China-a barometer of submerged macrophyte collapse. Aquat Conserv. 2011;21(1):82-91. https://doi.org/10.1002/aqc.1154.

46. Schmidt-Nielsen K. Animal physiology: adaptation and environment. Cambridge: Cambridge University Press; 1997.

47. Frederiksen M, Daunt F, Harris MP, Wanless S. The demographic impact of extreme events: stochastic weather drives survival and population dynamics in a long-lived seabird. J Anim Ecol. 2008;77(5):1020-9. https://doi.org/1 0.1111/j.1365-2656.2008.01422.x

48. Altwegg $R$, Roulin $A$, Kestenholz $M$, Jenni L. Demographic effects of extreme winter weather in the barn owl. Oecologia. 2006;149(1):44-51. https://doi. org/10.1007/s00442-006-0430-3

49. Harris J, Mirande C. A global overview of cranes: status, threats and conservation priorities. Chin Birds. 2013;4(3):189-209. https://doi.org/10. 5122/cbirds.2013.0025

50. Li F, Wu J, Harris J, Burnham J. Number and distribution of cranes wintering at Poyang Lake, China during 2011-2012. Chinese Birds. 2012;3(3):180-90. https://doi.org/10.5122/cbirds.2012.0027.

51. Barter M, Cao L, Chen L, Lei G. Results of a survey for waterbirds in the lower Yangtze floodplain, China, in January-February 2004. Forktail. 2005;21:1

52. BirdLife International. IUCN Red List for birds. 2020. Available online at: http://www.birdlife.org. Accessed 12 Jan 2020.

53. Wang W, Fraser JD, Chen J. Wintering waterbirds in the middle and lower Yangtze River floodplain: changes in abundance and distribution. Bird Conserv Int. 2017;27(2):167-86. https://doi.org/10.1017/S0959270915000398.

54. Jiao S, Zeng Q, Sun G, Lei G. Improving conservation of cranes by modeling potential wintering distributions in China. J Res Ecol. 2016;7:44-50.

55. Barzen J, Engels M, Burnham J, Harris J, Wu G. Potential impacts of a water control structure on the abundance and distribution of wintering waterbirds at Poyang Lake. Baraboo: International Crane Foundation; 2009.

56. Chen B, Cui P, Liu G, Li F, Wu X, Wu J, et al. Relationships between changing water levels and numbers of wintering tuber-eating birds in Poyang Lake National Nature Reserve. J Lake Sci. 2014;26:243-52.

57. Hou J, Liu Y, Fraser JD, Li L, Zhao B, Lan Z, et al. Drivers of a habitat shift by critically endangered Siberian cranes: evidence from long-term data. Ecol Evol. 2020;10(20):11055-68. https://doi.org/10.1002/ece3.6720.

58. Hu Z, Lin Y. Analysis of evolution process and driving factors for aquatic vegetations of Poyang Lake in 30 years. Resour Environ Yangtze Basin. 2019; 28:1947-55.

59. Jian M, Jian M, Li L, Wang S, Yu H, Yu G. Distribution pattern of submerged plants in typical wetlands of Poyang Lake and its influencing factors of water environment. Resour Environ Yangtze Basin. 2015;24:765-72.

60. Li Y, Zhong Y, Shao R, Yan C, Jin J, Shan J, et al. Modified hydrological regime from the three gorges dam increases the risk of food shortages for wintering waterbirds in Poyang Lake. Global Ecol Conserv. 2020;24:e01286. https://doi.org/10.1016/j.gecco.2020.e01286.

61. Wang W, Wang L, Hou J. Man-made habitats have become important foraging areas of Siberian cranes. Chinese J Wildlife. 2019;40:133-7.

62. Hou J, Wang Y, Jin B, Wang L, Wang W. Food composition of Siberian cranes in agricultural fields in the Poyang Lake, China. Chinese J Zool. 2019; 54:15-21.

63. Zhong Y, Li Y. Numerical change of cranes in rice paddies at Poyang Lake. China Crane News. 2018;22:3-4.

64. Li Y. Rice paddy use by water birds at Poyang Lake. China Crane News. 2018;22:25-6.

65. Pompanon F, Deagle BE, Symondson WOC, Brown DS, Jarman SN, Taberlet $P$. Who is eating what: diet assessment using next generation sequencing. Mol Ecol. 2012;21(8):1931-50. https://doi.org/10.1111/j.1365-294X.2011.054 03.x.

66. Hope PR, Bohmann K, Gilbert MTP, Zepeda-Mendoza ML, Razgour O, Jones $\mathrm{G}$. Second generation sequencing and morphological faecal analysis reveal unexpected foraging behaviour by Myotis nattereri (Chiroptera, Vespertilionidae) in winter. Front Zool. 2014;11(1):39. https://doi.org/10.11 86/1742-9994-11-39

67. Lin X, Hu S, Liu S, Huang H. Unexpected prey of juvenile spotted scat (Scatophagus argus) near a wharf: the prevalence of fouling organisms in stomach contents. Ecol Evol. 2018;8(16):8547-54. https://doi.org/10.1002/ece3.4380.

68. Symondson W. Molecular identification of prey in predator diets. Mol Ecol. 2002;11(4):627-41. https://doi.org/10.1046/j.1365-294X.2002.01471.X.

69. Razgour O, Clare EL, Zeale MR, Hanmer J, Schnell IB, Rasmussen M, et al. High-throughput sequencing offers insight into mechanisms of resource partitioning in cryptic bat species. Ecol Evol. 2011;1(4):556-70. https://doi. org/10.1002/ece3.49.

70. Yang Y, Zhan A, Cao L, Meng F, Xu W. Selection of a marker gene to construct a reference library for wetland plants, and the application of metabarcoding to analyze the diet of wintering herbivorous waterbirds. PeerJ. 2016;4:e2345. https://doi.org/10.7717/peerj.2345.

71. Zeale MR, Butlin RK, Barker GL, Lees DC, Jones G. Taxon-specific PCR for DNA barcoding arthropod prey in bat faeces. Mol Ecol Resour. 2011;11(2): 236-44. https://doi.org/10.1111/j.1755-0998.2010.02920.x

72. Deagle BE, Kirkwood R, Jarman SN. Analysis of Australian fur seal diet by pyrosequencing prey DNA in faeces. Mol Ecol. 2009;18(9):2022-38. https:// doi.org/10.1111/j.1365-294X.2009.04158.X.

73. Srivathsan A, Sha JC, Vogler AP, Meier R. Comparing the effectiveness of metagenomics and metabarcoding for diet analysis of a leaf-feeding monkey (Pygathrix nemaeus). Mol Ecol Resour. 2015;15(2):250-61. https://doi. org/10.1111/1755-0998.12302.

74. Gerwing TG, Kim J-H, Hamilton DJ, Barbeau MA, Addison JA. Diet reconstruction using next-generation sequencing increases the known ecosystem usage by a shorebird. Auk. 2016;133(2):168-77. https://doi.org/1 0.1642/AUK-15-176.1.

75. De Barba M, Miquel C, Boyer F, Mercier C, Rioux D, Coissac E, et al. DNA metabarcoding multiplexing and validation of data accuracy for diet assessment: application to omnivorous diet. Mol Ecol Resour. 2014;14(2): 306-23. https://doi.org/10.1111/1755-0998.12188.

76. Xiong M, Shao X, Long Y, Bu H, Zhang D, Wang D, et al. Molecular analysis of vertebrates and plants in scats of leopard cats (Prionailurus bengalensis) in Southwest China. J Mammal. 2016;97(4):1054-64. https://doi.org/10.1093/ jmammal/gyw061.

77. Zhong Y, Li Y. Waterbirds wintering in artificial wetland at Poyang Lake in winter 2018/2019. China Crane News. 2019:23:4-8.

78. Valentini A, Miquel C, Nawaz MA, Bellemain E, Coissac E, Pompanon F, et al. New perspectives in diet analysis based on DNA barcoding and paralle pyrosequencing: the trnL approach. Mol Ecol Resour. 2009;9(1):51-60. https://doi.org/10.1111/j.1755-0998.2008.02352.x.

79. Deagle BE, Thomas AC, Mclnnes JC, Clarke LJ, Vesterinen EJ, Clare EL, et al. Counting with DNA in metabarcoding studies: how should we convert sequence reads to dietary data? Mol Ecol. 2019;28(2):391-406. https://doi. org/10.1111/mec.14734.

80. Dahl KA, Patterson WF, Robertson A, Ortmann AC. DNA barcoding significantly improves resolution of invasive lionfish diet in the northern Gulf of Mexico. Biol Invasions. 2017;19(6):1917-33. https://doi.org/10.1007/s1 0530-017-1407-3.

81. Ando H, Setsuko S, Horikoshi K, Suzuki H, Umehara S, Inoue-Murayama M, et al. Diet analysis by next-generation sequencing indicates the frequent consumption of introduced plants by the critically endangered red-headed wood pigeon (Columba janthina nitens) in oceanic island habitats. Ecol Evol. 2013;3(12):4057-69. https://doi.org/10.1002/ece3.773.

82. Swanson GA, Bartonek JC. Bias associated with food analysis in gizzards of blue-winged teal. J Wildlife Manage. 1970;34(4):739-46. https://doi.org/10.23 07/3799138.

83. Bartonek JC. Summer foods and feeding habits of diving ducks in Manitoba vol. 113. Madison: University of Wisconsin; 1968.

84. Johnsgard PA. Cranes of the world. Lincoln: Indiana University Press; 1983.

85. Zeng N, Ji W, Huang Z, Liu Y, Jia D. Study on Siberian Cranes. In: Study on Jiangxi Poyang Lake National Nature Reserve. Wu Y, Ji W. Nanchang: China Forestry Publishing House; 2002:135-137.

86. Jiao S, Jiang K, Zuo A, Wu M, Lei G, Zhou Y. Foraging behavior and food resources of wintering Grus monacha in China. Sichuan J Zool. 2017;36:392-7.

87. Cheng Y. Home range and habitat selection of wintering white-naped crane Grus vipio through GPS telemetry in Poyang Lake, China. Beijing: Beijing Forestry University; 2015. Master Thesis 
88. Meine C, Archibald G. The cranes: status survey and conservation action plan. Gland and Cambridge: IUCN; 1996.

89. Wu J, Li F, Burnham J. Numerical distribution of Siberian cranes and their relation to food and water depth in Sha Hu at Poyang Lake, China. Wetland Sci. 2013;11:305-12.

90. Ding W, Zhou F. Research on wintering distribution of Siberian cranes. In: China bird Researchs. Edited by Gao W. Beijing: Science Press; 1991.

91. Harris J, Liying S, Higuchi H, Ueta M, Zhengwang Z, Yanyun Z, et al. Migratory stopover and wintering locations in eastern China used by Whitenaped Cranes Grus vipio and Hooded Cranes G. monacha, as determined by satellite tracking. Forktail. 2000;16:93-100.

92. Jiang J. Study on abundance and distribution of wintering waterbirds and ecological habits of four crane species in Poyang Lake. Nanchang: Jiangxi Normal University; 2016. Master Thesis

93. Zhang L, Yin J, Jiang Y, Wang H. Relationship between the hydrological conditions and the distribution of vegetation communities within the Poyang Lake National Nature Reserve, China. Ecol Inform. 2012;11:65-75. https://doi.org/10.1016/j.ecoinf.2012.05.006.

94. Zhang M, Ni L, Xu J, He L, Fu H, Liu Z. Annual dynamics of the wetland plants community in Poyang Lake in response to water-level variations. Res Environ Sci. 2013;26:1057-63.

95. Wang L, Dronova I, Gong P, Yang W, Li Y, Liu Q. A new time series vegetation-water index of phenological-hydrological trait across species and functional types for Poyang Lake wetland ecosystem. Remote Sens Environ. 2012;125:49-63. https://doi.org/10.1016/j.rse.2 012.07.003.

96. Wan W, Zhou L, Song Y. Shifts in foraging behavior of wintering hooded cranes (Grus monacha) in three different habitats at Shengjin Lake, China. Avian Res. 2016;7(1):13. https://doi.org/10.1186/s40657-016-0047-0.

97. Han Z, Wang S, Liu X, Peng W, Ge G, Huang A. Ecological thresholds for the dominated wetland plants of Poyang Lake along the gradient of flooding duration. J Hydraul Eng. 2019:50:252-62.

98. Ma Z, Li B, Zhao B, Jing K, Tang S, Chen J. Are artificial wetlands good alternatives to natural wetlands for waterbirds?-a case study on Chongming Island, China. Biodivers Conserv. 2004;13(2):333-50. https://doi. org/10.1023/B:BIOC.0000006502.96131.59.

99. Czech HA, Parsons KC. Agricultural wetlands and waterbirds: a review. Waterbirds. 2002;25:56-65.

100. Amano T. Conserving bird species in Japanese farmland: past achievements and future challenges. Biol Conserv. 2009;142(9):1913-21. https://doi.org/1 0.1016/j.biocon.2008.12.025

101. Sundar KSG, Subramanya S. Bird use of rice fields in the Indian subcontinent. Waterbirds. 2010;33(sp1):44-70. https://doi.org/10.1675/063.033.s104.

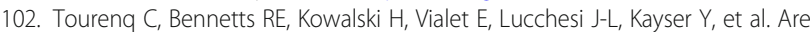
ricefields a good alternative to natural marshes for waterbird communities in the Camargue, southern France? Biol Conserv. 2001;100(3):335-43. https://doi.org/10.1016/S0006-3207(01)00037-4

103. Masero JA. Assessing alternative anthropogenic habitats for conserving waterbirds: Salinas as buffer areas against the impact of natural habitat loss for shorebirds. Biodivers Conserv. 2003;12(6):1157-73. https://doi.org/10.1 023/A:1023021320448

104. Fox AD, Abraham KF. Why geese benefit from the transition from natural vegetation to agriculture. Ambio. 2017;46(S2):188-97. https://doi.org/10.1 007/s13280-016-0879-1.

105. Nilsson L, Bunnefeld N, Persson J, Mansson J. Large grazing birds and agriculture-predicting field use of common cranes and implications for crop damage prevention. Agric Ecosyst Environ. 2016;219:163-70. https://doi. org/10.1016/j.agee.2015.12.021

106. Nowald G. In: Baraboo HJ, editor. Cranes and people: agricultural and tourism. In: Cranes, Agriculture, and Climate Change. Wisconsin: International Crane Foundation; 2010. p. 65-70.

107. Fox AD, Madsen J. Threatened species to super-abundance: the unexpected international implications of successful goose conservation. Ambio. 2017; 46(S2):179-87. https://doi.org/10.1007/s13280-016-0878-2.

108. Fasola M, Rubolini D, Merli E, Boncompagni E, Bressan U. Long-term trends of heron and egret populations in Italy, and the effects of climate, humaninduced mortality, and habitat on population dynamics. Popul Ecol. 2010; 52(1):59-72. https://doi.org/10.1007/s10144-009-0165-1.

109. Toral GM, Figuerola J. Unraveling the importance of rice fields for waterbird populations in Europe. Biodivers Conserv. 2010;19(12):3459-69. https://doi. org/10.1007/s10531-010-9907-9.
110. Baasch DM, Farrell PD, Pearse AT, Brandt DA, Caven AJ, Harner MJ, et al. Diurnal habitat selection of migrating whooping crane in the Great Plains. Avian Conserv Ecol. 2019;14:6.

111. Wang Z, Li Z, Beauchamp G, Jiang Z. Flock size and human disturbance affect vigilance of endangered red-crowned cranes (Grus japonensis). Biol Conserv. 2011:144(1):101-5. https://doi.org/10.1016/j.biocon.2010.06.025.

112. Zhao Q, Wang X, Cao L, Fox AD. Why Chinese wintering geese hesitate to exploit farmland. Ibis. 2018;160(3):703-5. https://doi.org/10.1111/ibi.12605.

113. Yu H, Wang $X$, Cao L, Zhang L, Jia Q, Lee $H$, et al. Are declining populations of wild geese in China 'prisoners' of their natural habitats? Curr Biol. 2017; 27(10):R376-7. https://doi.org/10.1016/j.cub.2017.04.037.

114. Shao M, Gong H, Dai N, Zhi Y, Xu N, Lu P. Study on time budgets and behavioral rhythm of wintering Siberian cranes in a lotus pond reclamation area in Poyang Lake. Acta Ecol Sinica. 2018;38:5206-12.

115. Sparling DW, Krapu GL. Communal roosting and foraging behavior of staging Sandhill cranes. Wilson Bull. 1994;106:62-77.

116. Nilsson L, Persson J, Bunnefeld N, Månsson J. Central place foraging in a human-dominated landscape: how do common cranes select feeding sites? Avian Biol. 2020:51:e02487.

117. Anteau MJ, Sherfy MH, Bishop AA. Location and agricultural practices influence spring use of harvested cornfields by cranes and geese in Nebraska. J Wildlife Manage. 2011;75(5):1004-11. https://doi.org/10.1002/ jwmg.135.

118. Choi C-Y, Takekawa JY, Xiong Y, Liu Y, Wikelski M, Heine G, et al. Tracking domestic ducks: a novel approach for documenting poultry market chains in the context of avian influenza transmission. J Integr Agr. 2016;15(7):158494. https://doi.org/10.1016/S2095-3119(15)61292-8.

119. Agosta SJ, Morton D, Kuhn KM. Feeding ecology of the bat Eptesicus fuscus: 'preferred' prey abundance as one factor influencing prey selection and diet breadth. J Zool. 2003;260(2):169-77. https://doi.org/10.1017/S0952836903003 601.

120. Khadka KK, Singh N, Magar KT, James DA. Dietary composition, breadth, and overlap between seasonally sympatric Himalayan musk deer and livestock: conservation implications. J Nat Conser. 2017;38:30-6. https://doi.org/10.101 6/j.jnc.2017.06.001

121. Lei J, Jia Y, Wang Y, Lei G, Lu C, Saintilan N, et al. Behavioural plasticity and trophic niche shift: how wintering geese respond to habitat alteration. Freshw Biol. 2019;64(6):1183-95. https://doi.org/10.1111/fwb.13294.

122. Krebs JR, McCleery RH. Optimization in behavioural ecology. In: Krebs JR, Davies NB, editors. Behavioural ecology: an evolutionary approach. Sunderland: Sinauer Associates; 1984

123. Stephens DW, Krebs JR. Foraging theory. Princeton: Princeton University Press; 1986

124. Kacelnik A. Information primacy or preference for familiar foraging techniques? A critique of Inglis \& Ferguson. Anim Behav. 1987;35(3):925-6. https://doi.org/10.1016/S0003-3472(87)80130-6.

125. Durson AM, Willson JD, Winne CT. Habitat influences diet overlap in aquatic snake assemblages. J Zool. 2013;291(3):185-93. https://doi.org/10.1111/jzo.12 061.

126. Luiselli L. Interspecific relationships between two species of sympatric Afrotropical water snake in relation to a seasonally fluctuating food resource. J Trop Ecol. 2006;22(1):91-100. https://doi.org/10.1017/S02664674 05002877

127. Steenhof K, Kochert MN. Dietary shifts of sympatric buteos during a prey decline. Oecologia. 1985:66(1):6-16. https://doi.org/10.1007/BF00378546.

128. de Carvalho TC, de Assis Montag LF, dos Santos-Costa MC. Diet composition and foraging habitat use by three species of water snakes, Helicops Wagler, 1830, (Serpentes: Dipsadidae) in eastern Brazilian Amazonia. J Herpetol. 2017;51:215-22.

129. Wang W, Fraser JD, Chen J. Distribution and long-term population trends of wintering waterbirds in Poyang Lake, China. Wetlands. 2019;39(Suppl 1): S125-35.

130. Min Q. On the regularites of water level fluctuations in Poyang Lake. J Lake Sci. 1995;7:281-8

131. Feng L, Hu C, Chen X, Cai X, Tian L, Gan W. Assessment of inundation changes of Poyang Lake using MODIS observations between 2000 and 2010. Remote Sens Environ. 2012;121:80-92. https://doi.org/10.1016/j.rse.2 012.01.014.

132. Hu Z, Zhang Z, Liu Y, Ji W, Ge G. The function and significance of the shallow-lakes in the Poyang Lake wetland ecosystem. Jiangxi Hydraul Sci Techn. 2015;41:317-23. 
133. Li Y, Qian F, Silbernagel J, Larson H. Community structure, abundance variation and population trends of waterbirds in relation to water level fluctuation in Poyang Lake. J Great Lakes Res. 2019;45(5):976-85. https://doi. org/10.1016/j.jglr.2019.08.002.

134. Barzen J. Studying and understanding wetland dynamics. In: Li F, Liu G, Wu J, Zeng N, Harris J, Jin J, editors. Ecological Study of Wetlands and Waterbirds at Poyang Lake. Beijing: Popular Science Press; 2012. p. 256-66.

135. Ponomarev A, Tatarinova T, Bubyakina V, Smagulova F, Morozov I, Kashentseva T, et al. Genetic diversity in Siberian crane (Grus leucogeranus) based on mitochondrial DNA D-loop polymorphism. Doklady Biol Sci. 2004; 397(1-6):321-3. https://doi.org/10.1023/B:DOBS.0000039704.91688.ca.

136. Taberlet $P$, Coissac E, Pompanon F, Gielly L, Miquel C, Valentini A, et al. Power and limitations of the chloroplast trnL (UAA) intron for plant DNA barcoding. Nucleic Acids Res. 2007;35(3):e14. https://doi.org/10.1093/nar/ gkl938.

137. Magoč T, Salzberg SL. FLASH: fast length adjustment of short reads to improve genome assemblies. Bioinformatics. 2011;27(21):2957-63. https:// doi.org/10.1093/bioinformatics/btr507.

138. Caporaso JG, Kuczynski J, Stombaugh J, Bittinger K, Bushman FD, Costello EK, et al. QIIME allows analysis of high-throughput community sequencing data. Nat Meth. 2010;7(5):335-6. https://doi.org/10.1038/nmeth.f.303.

139. Edgar RC. Search and clustering orders of magnitude faster than BLAST. Bioinformatics. 2010;26(19):2460-1. https://doi.org/10.1093/bioinformatics/ btq461.

140. Colwell RK. EstimateS: Statistical estimation of species richness and shared species from samples. Retrieved from http://purl.oclc.org/estimates. 2006.

141. Levins R. Evolution in changing environments. Princeton: Princeton University Press; 1968. https://doi.org/10.1515/9780691209418.

142. Hurlbert SH. The measurement of niche overlap and some relatives. Ecology. 1978;59(1):67-77. https://doi.org/10.2307/1936632.

143. Pianka ER. The structure of lizard communities. Annu Rev Ecol Syst. 1973; 4(1):53-74. https://doi.org/10.1146/annurev.es.04.110173.000413.

144. Gotelli NJ, Ellison AM. EcoSimR. Version 1.00. Retrieved from http://www. uvm.edu/ ngotelli/EcoSim/EcoSim.html. 2013.

145. Oksanen J, Blanchet FG, Kindt R, Legendre P, Minchin PR, O'hara R, Simpson GL, Solymos P, Stevens MHH, Wagner H. vegan: Community Ecology Package. Retrieved from http://CRAN.R-project.org/package=vegan. 2013.

146. Wickham H. ggplot2: elegant graphics for data analysis. New York: Springer; 2016. https://doi.org/10.1007/978-3-319-24277-4.

\section{Publisher's Note}

Springer Nature remains neutral with regard to jurisdictional claims in published maps and institutional affiliations.

Ready to submit your research? Choose BMC and benefit from:

- fast, convenient online submission

- thorough peer review by experienced researchers in your field

- rapid publication on acceptance

- support for research data, including large and complex data types

- gold Open Access which fosters wider collaboration and increased citations

- maximum visibility for your research: over $100 \mathrm{M}$ website views per year

At $\mathrm{BMC}$, research is always in progress.

Learn more biomedcentral.com/submissions 